\title{
Current Treatment Approaches for Melasma
}

\section{Özlem SU KÜÇÜK}

Department of Dermatology, Bezmialem Vakif University School of Medicine, İstanbul, Turkey

\section{ABSTRACT}

Melasma is a common acquired pigmentary disorder and is particularly seen among Asians and Hispanics. It is characterized by greyishbrown patches in areas of the face exposed to the sun, such as the forehead, cheeks, lips, and nose. Melasma has a psychological effect on affected patients and can reduce their quality of life. Since long, it has been a frustrating condition in terms of treatment for both dermatologists and patients. Continuous strict sun protection and avoding other triggers are essential. Hydroquinone is the most commonly used agent in topical monotherapy. A topical triple-combination formula is still the gold standard for treating melasma. Chemical peels and lasers lead to a high risk of post-inflammatory pigmentation. Oral tranexamic acid may be considered for those who fail or who only partially respond to conventional therapy; however, further studies are required to fully elucidate the efficacy and safety of this agent. Understanding dermal changes and the importance of vascularization in the pathogenesis of melasma will result in the development of new treatment options.

Keywords: Melasma, acquired pigmentary disorder, current, treatment approaches

\section{Introduction}

Melasma is the condition that most commonly causes skin pigmentation. Known as chloasma or chloasma gravidarum (mask of pregnancy), it typically occurs on the face, affecting cheeks, forehead, and chin as these are frequently exposed to the sun. It is characterized by symmetrical and confluent gray-brown patches. Melasma is a cosmetic problem that can sometimes cause major emotional issues. The depigmentation provided by the majority of current treatments is temporary, and recurrences are frequent. However, there are various beneficial treatment methods (1-3).

\section{Clinical and Research Effects}

\section{Definition and epidemiology}

Melasma is a word originating from Greek melas, meaning "black." It is a very common hypermelanosis, characterized by well-demarcated gray-brown patches that occur frequently on sun-exposed areas of the face and rarely on the neck and forearms. It is a chronic and recurrent disease that negatively affects the quality of life. Although seen in all races, it is much more frequent in people of Latin American, Asian, African, or Middle Eastern origin $(1,2)$. Prevalence shows geographical variations: $9 \%$ in Hispanics in South America and 40\% in Southeast Asians (3). While melasma is reported as the most common pigmentation disorder among Indians, it is reported as the third most common pigmentary disease among individuals with brown to light-brown skin (4). It is mostly seen in women; 90\% of individuals who develop melasma are females (1).

\section{Etiopathogenesis}

Although the pathogenesis of melasma is not precisely known, it is regarded as a condition initiated by biologically active melanocytes (5). The most important factors considered to play a role in etiopathogenesis are genetic effects, contact

Cite this article as: Küçük ÖS. Current Treatment Approaches for Melasma. Bezmialem Science 2018; 6: 54-62. 
with ultraviolet (UV) light, and female sex hormones $(1,2)$. Other possible factors include thyroid dysfunctions, cosmetics, phototoxic and antiepileptic drugs, ovarian and hepatic dysfunction, and nutritional deficiencies (1). UV acts as a major triggering and exacerbating factor in the development of melasma by acting directly on melanocytes $(1,2,6)$. Genetic susceptibility has been reported to play a role in the development of melasma $(7,8)$. Natural and synthetic estrogens and progesterone are implicated in etiopathogenesis because of the increased incidence of melasma in relation to pregnancy, oral contraceptive use, and estrogen replacement therapy. Since melanocytes contain the estrogen receptor, melanocytes of patients with melasma are naturally more sensitive to the stimulatory effects of estrogens and possibly other sex steroids (1). Histopathologic evaluations of melasma lesions have shown greatly increased elastosis and vascularization in the perilesional skin, in addition to increased pigmentation $(1,2$, $9,10)$. There was no increase in the number of melanocytes in these regions, but melanocytes were found to be larger, and with highly distinct dendrites, these melanocytes were more intensely stained. An increase in melanogenesis was detected (1). Compared to the surrounding healthy area, the increase in vascularization in the melasma lesions was also confirmed by confocal microscopy (11). Recent studies have pointed to the role of stem cell factor and vascular, dermal, and neural components in the pathogenesis of melasma $(1,2,12,13)$.

\section{Clinical findings}

Melasma is characterized by well-demarcated and irregularly demarcated light-to-dark brown or brown-gray hyperpigmented patches. The number of hyperpigmented patches can range from a single lesion to multiple lesions. The patches are usually localized symmetrically on the forehead, cheeks, dorsum of the nose, the upper lip, chin, neck circumference, and forearms. Extra-facial melasma is much more common in postmenopausal women. It can be seen in three different patterns according to the distribution of the lesions $(1,2)$ :

1. Centrofacial pattern: This pattern is the most common pattern. The forehead, cheeks, upper lip, nose, and chin are affected.

2. Malar pattern: This pattern affects the cheeks and nose.

3. Mandibular pattern: This pattern affects the mandibular protrusion.

Melasma is divided into four types, based on the pigment localization according to the extensive examination with Wood's light. These are the epidermal, dermal, mixed, and unnamed type.

Epidermal type: Increased pigmentation in the light-brown color and under the Wood's light.

Histologically, it is characterized by an increase in melanin in the basal, suprabasal, and stratum corneum.
Dermal type: This is a type with gray or bluish-gray color, and it shows no change in pigmentation under the Wood's light. Histologically, most of the melanophages are in the superficial and deep dermis.

Mixed type: This type is dark brown. Whereas an increase in pigmentation is observed in some regions under the Wood's light, in other regions it is not. Melanin is increased in the epidermis. Dermal melanophages are numerous.

Unnamed type: For people with dark-brown skin or phototype VI, Wood's light is of no use. Therefore, the type of melasma cannot be determined.

The MASI score is a commonly used method to assess the severity of melasma. It is mostly used in clinical trials to evaluate patients with melasma. Three factors are subjectively evaluated to calculate the MASI score $(0-48)(1,2,6)$ :

- The area of involvement (A)

- Darkness(D)

- The homogeneity of color $(\mathrm{H})$

A is calculated for four regions; forehead (f) $30 \%$, right malar region $(\mathrm{rm}) 30 \%$, left malar region $(\mathrm{lm}) 30 \%$, and chin (c) region $10 \%$. For each of these four regions, the involvement area is expressed by a numerical value ranging from 0 to $6(0=$ no involvement; $1 \leq 10 \% ; 2=10 \%-29 \% ; 3=30 \%-49 \%$; $4=50 \%-69 \% ; 5=70 \%-89 \% ; 6=90 \%-100 \%)$. D and $\mathrm{H}$ are indicated by a scale ranging from 0 to $4(0=$ none; $1=$ mild; $2=$ moderate; $3=$ significant; $4=$ very severe). When MASI is calculated, the degree of darkness and color homogeneity are summed and multiplied by the area of involvement for each facial region $(2,6)$.

MASI total score $=0.3 \mathrm{~A}(\mathrm{f}) \mathrm{D}(\mathrm{f}) \mathrm{H}(\mathrm{f})+0.3 \mathrm{~A}(\mathrm{~lm}) \mathrm{D}(\mathrm{lm}) \mathrm{H}(\mathrm{lm})$ $+0.3 \mathrm{~A}(\mathrm{rm}) \mathrm{D}(\mathrm{rm}) \mathrm{H}(\mathrm{rm})+0.1 \mathrm{~A}(\mathrm{c}) \mathrm{D}(\mathrm{c}) \mathrm{H}(\mathrm{c})$.

Recently, modified homogeneity m(MASI) has been developed since calculation can be problematic due to individual differences. In mMASI, homogeneity component is not calculated. Calculation of this score is more practical for the clinician. The mMASI score ranges between 0 and 24 (2).

mMASI total score $=0.3 \mathrm{~A}(\mathrm{f}) \mathrm{D}(\mathrm{f})+0.3 \mathrm{~A}(\mathrm{~lm}) \mathrm{D}(\mathrm{lm})+0.3 \mathrm{~A}(\mathrm{rm})$ $\mathrm{D}(\mathrm{rm})+0.1 \mathrm{~A}(\mathrm{c}) \mathrm{D}(\mathrm{c})$.

\section{Diagnosis}

Diagnosis of melasma is made clinically. Pregnancy, oral contraceptive use, family history, sun exposure, and medical history also provide useful information for diagnosis (1).

\section{Differential diagnosis}

The differential diagnosis of melasma should be made with post-inflammatory pigmentation, pigmented cosmetic dermatitis, hyperthyroidism, actinic lichen planus, HIV-associated pigmentation, drug-induced facial pigmentation, and 
poikiloderma of Civatte. The histories (for post-inflammatory pigmentation, cosmetic dermatitis, and drug-induced pigmentation), clinical findings (for cosmetic dermatitis, actinic lichen planus, drug-induced pigmentation, and poikiloderma of Civatte), laboratory tests (for thyroid function tests, HIV serology, hyperthyroidism, and HIV-associated pigmentation), patch tests (for cosmetic dermatitis), and histopathology are useful for diagnosis (2).

\section{Treatment}

Treatment should target the four main mechanisms (1):

1. Suppression of the activity of melanocytes (protection from sunlight and avoiding triggering factors)

2. Suppression of melanin synthesis (depigmenting agents)

3. Removal of melanin (chemical peeling)

4. Scattering melanin granules (lasers)

Treatment should be shaped according to clinical subtype and severity (1).

1. Suppression of the activity of the melanocytes: Exposure to sunlight is one of the most important risk factors. In melasma, melanocytes are easily stimulated by UVA, UVB, and also visible light $(\mathrm{VL})$. Broad-spectrum sun protection should be applied both during and after treatment. To protect oneself from the sun, it is necessary to try to stay in the shade and avoid sun exposure, especially between 10:00 and 15:00, to wear sun protective clothing such as a long-sleeved T-shirt and a wide-brimmed hat, to use a broad-spectrum sun protection factor (SPF) of at least 30, and a combined sunscreen containing a physical preservative such as titanium dioxide and to repeatedly apply it during the day. The use of broad-spectrum sun protection is important for two reasons. In most studies, VL and UV light have been shown to cause pigment changes in all skin types $(1,2)$. Broad-spectrum sunscreens enhance the activity of hydroquinone (HQ). In another study, it was reported that in people with skin types IV-VI, UVA-1, and
VL stimulated pigmentation, and this stimulated pigmentation is darker and more permanent (14). Opaque sunscreens such as titanium dioxide or zinc oxide (especially the addition of an agent that absorbs pigments such as iron oxide to the sunscreen) are much more effective in protection against VL than chemical sunscreens. In the treatment of difficult cases, opaque sunscreens containing iron oxide should especially come to mind. Avoiding artificial UV light should also be recommended. Being strict about avoiding sun exposure may raise concerns regarding vitamin D levels. Although it is not a clearly supported view, testing for and supporting the baseline vitamin $\mathrm{D}$ level of the patient seems to be a rational approach. However, there is a need for new studies on this subject (2).

2. Suppression of melanin synthesis (depigmenting agents): The rate-limiting step in the production of melanin is the conversion of tyrosine to L-3,4-dihydroxyphenylalanine (L-DOPA) with L-tyrosinase. The main target in the topical treatment of melasma is L-DOPA. For this reason, most of these agents are tyrosinase inhibitors. The production of melanin starts with tyrosine. By means of the tyrosinase enzyme in the melanosomes, first dopaquinone and then melanin occurs. The melanosomes loaded with the melanin move into the keratinocytes by moving along the dendrites of the melanocytes. The keratinocytes are thus colored. The depigmenting agents are divided into three types (Table 1) (1):

1. Phenolic compounds

2. Non-phenolic compounds

3. Combination formulas

\section{Phenolic compounds}

\section{Hydroquinone (HQ)}

It is a tyrosinase-inhibitor-hydroxyphenolic compound. It is the oldest and most commonly used depigmenting agent. It is the gold standard in the treatment of melasma. It prevents the RNA and DNA synthesis of melanocytes, breaks

\section{Table 1. Depigmentation agents}

$\begin{array}{ll}\text { Phenolic Compounds } & \text { Non-phenolic Compounds } \\ \text { Hydroquinone } & \text { Azeleic acid } \\ \text { 4-isopropylcatechol } & \text { Retinoids } \\ \text { 4-hidroxianisol } & \text { L-ascorbic acid } \\ \text { Kojic acid } & \text { Thiocytic acid } \\ \mathrm{N} \text {-acetyl-glucosamine } & \text { N-acetylcysteine } \\ \text { 4-methoxyphenol } & \text { Licorice } \\ \mathrm{N} \text {-acetyl-4-S-cysteminylphenol } & \text { Corticosteroids } \\ & \text { 4-n-butylresorcinol } \\ & \text { Niacinamide } \\ & \text { Arbutine }\end{array}$

Combination Formulas

Kligman's formula

Modified Kligman's formula

Triple cream 
down melanosomes, and causes melanocyte necrosis. HQ is easily oxidized and loses its potency. For this reason, $0.1 \%$ sodium bisulfate and $0.1 \%$ ascorbic acid should be used in the form of antioxidants. The depigmenting effect of HQ can take about a few weeks to a few months to take effect after the procedure. Side effects are minimal when controlled and followed up. Short-term side effects depend on the dose and duration. Irritation, erythema, a tingling sensation, and irritant or allergic contact dermatitis may occur. Temporary halo-shaped hypochromia may occur in treated areas. In practice, the addition of agents such as tretinoin, glycolic acid, and sunscreen to HQ is usually responsible for excessive irritation. Mid- and long-term side effects are milia formation, paradoxical post-inflammatory hyperpigmentation (PIH), exogenous ochronosis (especially in dark phototypes). Persistent hypopigmentation, referred to as leukoderma en confetti, can be seen following the administration of a high-concentration HQ formula. Exogenous ochronosis is a rare situation characterized by the blue-black pigmentation in the treated melasma areas and histologically banana-shaped deposits on dermis. Essentially, it is seen among people with dark skin after a long-term administration of high-concentration $\mathrm{HQ}$, especially when used with resorcinol. It has also been reported that it was rarely seen among different races after a short period of low-concentration application (2\%). Some concerns have arisen about the safety of $\mathrm{HQ}$ in the last decade. In most countries in the world, the sale of $2 \%$ HQ formulas is prohibited, but can be purchased only with prescription $(1,2)$.

Kojic acid: Kojic acid consists of 5-hydroxy-4-pyran 4-1-2 methyl. It is a fungal metabolite (Aspergillus oryzae and Penicillum spp.). It inhibits the catecholase activity of tyrosinase and is a potent antioxidant; $2 \%-4 \%$ is used alone or in combination with tretinoin, $\mathrm{HQ}$, and/or corticosteroids. If used alone, it is less effective than 2\% HQ. However, it has a synergistic effect with the combination of $10 \%$ glycolic acid and $2 \%$ HQ (1).

\section{Non-phenolic compounds (1)}

- Azelaic acid

- Topical retinoids

- L-ascorbic acid (vitamin C, ASA)

- Arbutine

- Licorice extract

- Dioic acid

- Metimazol

- N-acetylcysteine

- Niacinamide

- Flutamide

Azelaicacid (AzA): It is procured from Pityrosporum ovale. It is a weak, reversible, and competing tyrosinase inhibitor. It also affects DNA synthesis and mitochondrial oxidoreduction. It has no effect on normal melanocytes, and there is antiproliferative and cytotoxic effect on abnormal melanocytes. It has anti-inflammatory, antibacterial, and antioxidant effects
(1). In a randomized, double-blind, carrier-comparative multicenter study on epidermal melasma in patients with skin types IV-VI, a significant improvement was observed in the group that used 20\% AzA (15). In one study, 20\% AzA was found to be superior to $2 \% \mathrm{HK}$ (16). In another study, $20 \%$ Aza was found to be as effective as $4 \% \mathrm{HK}$ (17). In a recent study, when 20\% AzA and 4\% HK were compared during a 2-month treatment, AzA was found to be significantly more effective than HQ. However, this study was not evaluated with objective measures, and after 2 months, clinical followup was not completed (18). The efficacy increases with topical tretinoin $(0.05 \%)$ and glycolic acid (10\%-20\%) combination (1). Side effects are minimal when AzA is used at a concentration of $10 \%-20 \%$ twice daily. The most frequently reported side effects are erythema, burning sensation, squama, and pruritus (2).

Topical retinoids: The efficacy of topical retinoids in the treatment of melasma has been proven (19). Topical retinoids have effects on keratinocytes, melanosomes, and melanin synthesis. They inhibit tyrosinase transcription and increase cell turnover. Thus, they cause rapid pigment loss through epidermopoesis (2).

- Tretinoine: It is usually applied at night at a concentration of $0.05 \%-0.1 \%$. Although it is effective as monotherapy, it is not as effective as HQ or combination therapies; it requires a 20 - to 40 -week treatment period. The most common side effects are the burning sensation, erythema, squama, and other irritation-related side effects. The incidence of side effects is $67 \%-88 \%$. Retinoid dermatitis leads to PIH, especially among individuals with dark skin (1).

- Adapalene: It is applied in a concentration of $0.1 \%$. It is a synthetic retinoid with less side effects compared to other retinoids. It is effective and safe in the treatment of epidermal melasma as a monotherapy (20).

L-ascorbic acid (vitamin C, ASA): It prevents melanin formation. It is effective due to its ability to bind copper ions (2). It is usually formulated with other depigmenting agents such as HQ at a $5 \%-10 \%$ concentration. It has antioxidant, anti-inflammatory, and photoprotective effects (1). It is ineffective as a monotherapy because this agent does not have a high stability and is rapidly oxidized. An efficiency enhancement can be achieved with soy or licorice extracts. It is a good adjuvant therapy agent, and it reduces skin irritation when used in patients who cannot tolerate HQ (2). It can be used with iontophoresis since vitamin $\mathrm{C}$ increases the level of skin absorption $(1,2)$.

Arbutine/Deoxy arbutine: It is a HQ derived from blueberries and Phytolacca americana; 3\% arbutin may provide depigmentation, but hyperpigmentation results from its use at high concentrations (21). This agent is included in most of the over-the-counter depigmentation creams. 
Licorice extract: Its active ingredients are liquiritin and isoliquiritin. It inhibits tyrosinase and has anti-inflammatory features. Twenty female patients were treated with liquiritin cream twice a day for over 4 weeks in a comparative study performed with carrier, and liquiritin was found to be superior to the carrier (22). There are several depigmentation creams being sold over-the-counter, but there is not enough clinical evidence of its efficacy.

Rucinol (0.3\% serum): It is a phenol derivative. Twelve weeks after a prospective, double-blind, randomized, carrier-controlled study, a significant reduction in pigmentation score was reported (23).

Dioic acid: In a study that included 96 Mexican women who were treated twice a day for 12 weeks, dioic acid was found to be effective and well tolerated. There was no statistically significant difference in terms of side effects and efficacy when compared with HQ (2\%). Acne development was observed in $30 \%$ of treated patients (2).

Methimazole: It was used in the treatment of 2 patients with epidermal melasma. It is an oral antithyroid agent, and when used topically, it provides skin depigmentation without affecting the thyroid gland (24).

Other Agents: Many experimental agents are being investigated in the treatment of melasma. Plant extracts, aloesin, flavonoids, oregonin, green tea, orchid extracts, coumaric acid, and ellagic acid are among these agents. However, efficiency and reliability studies are lacking for these agents $(1,2)$.

Topical flutamide: In a randomized parallel study, comparative mexameter measurements showed that melasma 4\% HQ with $1 \%$ flutamide cream were found to be as effective as $\mathrm{HQ}$. However, the MASI score and patient satisfaction were better with flutamide (25).

\section{Combination Formulas}

Kligman-Willis formula: It consists of 5\% HQ, $0.1 \%$ tretinoin, and $0.1 \%$ dexamethasone (ethanol and propylene glycol 1:1 or in hydrophilic pomade). It is one of the first-developed combinations for hyperpigmentation treatment, and it has been used for over 30 years. To achieve clinical efficacy, an application of twice a day for approximately over 3 weeks is required (maximum 5-7 weeks). This formulation should never be older than 30 days since it is not protected by antioxidants (1). As the formulation maximizes the effectives, the irritation minimizes. It performs this effect in a much shorter time compared to each individual agent that it is consisted of. By this means, HQ oxidation and steroid atrophy are prevented, and epidermal transfer and cell turnover are increased. Thus, epidermis penetration of topical agents is facilitated. The formulation removes the irritation effect of steroid HQ and tretinoin. Effectiveness is reduced when one of these three components is removed (2). Combination treatments are much more effective than monotherapies. Usually, these combination treatments are administered at night and are continued with $2 \%$ HQ treatment.

Triple-Combination Cream: It is a modified version of Kligman and Willis formula containing 4\% HQ, 0.05\% tretinoin, and $0.01 \%$ fluosinolone acetonite (2). When applied in combination with a triple-combination cream sunscreen (SPF 30 ), a total or nearly total response rate was $77 \%$ in patients with melasma; however, this rate was $47 \%$ in patients who received dual treatment (26). The side effects of combination therapies are erythema, burning sensation, tingling sensation, irritation, xerosis, and scaling. In most patients, these side effects are mild. The triple-combination cream has the risk of skin irritation and PIH depending on the color of the skin. For this reason, it is more convenient to apply it in smaller amounts and less frequently. If irritation does not occur after a few weeks, daily application starts. This mixture, or commercially available cream, proved superior to single or dual treatments; after 6 months of use, atrophy was not observed, and the benefit-to-loss ratio was found to be superior (2).

\section{Other combination treatments}

- Combination of HQ, hyaluronic acid, and glycolic acid: It was used on 15 Latin American patients with melasma twice daily for 12 weeks, and a significant decrease in the MASI score and in the narrow-band-reflectance spectrophotometer (mexameter) was observed (27).

- HQ 4\%, buffered glycolic acid 10\%, ascorbic acid, and vitamin E sunscreen: In measurements performed with mexameter $(75 \%)$, it provided a significant benefit compared to the sunscreen group (13\%) (28).

- Linoleic acid $2 \%$, linkomycin $2 \%$, and betamethasone valerate $\mathbf{0 . 0 5 \%}$ : It was used on 47 patients with melasma in a double-blind randomized trial for 6 weeks and found to be significantly effective. New liposomal $(0.1 \%)$ formulations provide increased solubility compared to older formulations and thus increase efficacy at low concentrations (29).

Removal of melanin (chemical peeling): Peeling has been used in melasma therapy for years, particularly in resistant cases and with topical treatment (adjunctive therapy). The results are variable. The removal of melanin is much more effective in the epidermal type melasma and in individuals with light-colored skin. For the treatment to succeed, the regimens used before and after the treatment to increase the effectiveness and to minimize the PIH are as important as the correct selection of peeling. The type, concentration, frequency, and duration of administration of the applied agent are also important to achieve optimum success (2).

- Glycolic acid (GA): It is the most commonly used alpha-hydroxy-acid-peeling agent (at 20\%-70\% concentration). It is the most helpful peeling form of topical treatment; four to six sessions are administered every 
2-3 weeks. Treatment with HQ for 2 weeks before the procedure can both increase healing and reduce the pigmentation risk (2). Although there has not been any comparative published study of GA and salicylic acid on melasma, it has not yet been reported that GA is as effective and safe as salicylic acid, although there is no comparative published study examining GA and salicylic acid in melanoma treatment (2).

- Salicylic acid (SA): It reduces PIH by anti-inflammatory effects, and it diffuses bleaching effects. In one study, $75 \%$ of patients with melasma with dark skin showed a moderate improvement. The side effects have been observed as mild and transient, and the rate has been reported as $16 \%(30)$.

- Trichloroacetic acid: Although favorable results have been obtained in patients with light-colored skin with epidermal melasma at a concentration of $10 \%-20 \%$, it should be used with caution in patients with dark skin due to the risk of PIH and scarring after peeling (2).

- Lactic acid: Very few studies have shown comparable results with GA in individuals with darker skin color (2).

- Tretinoin: 4- to 6-month treatment period is required for weekly administrations at less than $1 \%$ concentrations to achieve skin depigmentation (2).

- Other peeling agents: Pyruvic acid, SA and mandelic acid combinations, phytic acid, Obagi blue peeling and amino fruit acid, light Jessner peeling (2).

Scattering melanin granules (lasers and light sources): This technology should be used in resistant cases. PIH is the most important side effect, and especially when skin phototypes are high, depigmenting agents are required before and after treatment (1). Intensive pulsed light (IPL), fractional lasers, and radiofrequency or pigment lasers (microseconds, picoseconds, Q-switched) can be used in melasma treatment (31).

Lasers: Various lasers and light systems are used in the treatment of melasma, and variable results are obtained. A great deal of treatment is needed, and repetition is frequent. Basically, chromophore melanin is the primary target of the melanosomes to initiate the laser damage (1). Sheth et al. (32) reported that Q-switched ruby and erbium-YAG lasers worsened melasma. The combination of $\mathrm{CO} 2$ laser and Qswitched alexandrite laser does not provide benefit in the treatment of melasma, and it can even initiate PIH in individuals with darker skin color. The only laser system approved by the FDA in 2003 with promising results in the treatment of melasma is non-ablative fractional lasers $(1,33)$.

Multiple microscopic zones of thermal damage are created leaving the majority of the skin intact (34). The most commonly used one from this group is the Fraxel laser $(34,35)$, an erbium fiber laser with a wavelength of 1550 nanometers. Fraxel lasers are as effective as ablative lasers, but with less risk of side effects and complications than ablative lasers. To avoid the risk of hyperpigmentation (especially in those with PIH history), administration of low-fluence and variable pulsing and the use of HQ up to 6 weeks prior to the procedure is recommended (1). The use of antiangiogenic lasers (copper bromide laser) for the treatment of melasma is based on the evidence showing an increased vascularization in melasma lesions as compared with the surrounding unaffected skin (1, 2, 9). Passeron et al. (36) presented significantly better results when Kligman's formula was used comparatively alone or in combination with PDL (spot width $7 \mathrm{~mm}$, pulse duration 20 $\mathrm{ms}$, energy, $10 \mathrm{j} / \mathrm{cm} \mathrm{2}$, dynamic cooling device, 30/40) and reported that fewer repetitions were required.

Intense pulsed light (IPL): It is a non-laser light source and emits light between a wavelength of 515-1200 nm. In different experiences of epidermal melasma, it has been observed that up to $70 \%-100 \%$ clearance of the basal might be provided, but the $\mathrm{PIH}$ risk is high. However, the results are poor or unfavorable in dermal and mixed melasma cases. The best approach is to use low energy and to keep long pulse intervals (1).

\section{Systemic Treatment}

Oral tranexamic acid (TA): Traditionally, it is an agent that has been used for bleeding diathesis and menorrhagia. However, it has been successfully used in Japan for the treatment of melasma (37). Although its mechanism of action is unknown, it decreases tyrosinase activity. Its probable efficacy focuses on mechanisms such as vascular endothelial growth factor and alpha MSH hormone (38). Its topical and intradermal forms are also used. However, several reports have suggested that the oral form is more potent and more suitable for the treatment of melasma. The most frequently reported side effects are headache, menstrual irregularity, nausea, and back pain. In the literature on women's health, it was reported that it was used in a dose of 3.9-4 g/day (4-5 days for each cycle). The side effects are minor or mild. There is no evidence of any thrombotic events at these doses (39). Cho et al. (37) evaluated adjuvant clinical efficacy and safety of oral TA for melasma. A total of 51 Korean women were either given 500 $\mathrm{mg}$ TA/day+IPL or 3-4 sessions of Q-switched Nd-YAG with low fluence or combined IPL and Q-switched Nd-YAG alone and TA-treated group was reported to have superior results ( $44 \%$ and $24 \%$, respectively). The results were evaluated by a dermatologist with mMASI. Na et al. (40) presented that TA has different impacts on lesion-free and lesioned skin. This study in which the melanocyte index score was measured via mexameter presented that melanocyte index score decreased in the lesioned skin, while melanocyte score increased in the lesion-free skin. In another study performed by Shin et al. (38), it was found that the efficacy of the Q-switched NdYAG laser with low fluence was increased by an 8-week administration of $750 \mathrm{mg} /$ day TA using the mMASI score. In this randomized study involving 48 Korean women, TA was well tolerated, and only 1 patient had gastroesophageal reflux, and nausea was observed in another patient. In a study comparing the use of flusinolone-based triple-combination cream alone and in combination with oral TA in melasma 
treatment, the efficacy of the treatment started faster, and the remission duration was longer in the group in which TA was used. However, there is a need for more extensive studies to assess the efficacy of this treatment. Maintenance of the treatment with a broad-spectrum sunscreen and a topical retinoid is the ideal approach (41).

\section{Future Treatments}

Endothelin B-receptor inhibitors (EDNRB): Stimulation of endothelin (EDN) -1 and stem cell factor placed in the melanogenic intracellular signal pathway leads to the activation of melanogenesis, so inhibitors of endothelin B-receptor
(EDNRB) may suppress melanogenesis (42).

Chemical approaches: New chemical approaches can be beneficial to prevent pigmentation caused by VL (new agents that suppress melanin synthesis).

\section{Conclusion}

Melasma treatment often leads to a long-lasting frustration both for the doctor and the patient. New therapies are creating excitement. It is essential to avoid sunlight and other triggering factors. Topical triple cream is still the gold standard in the treatment. HQ $(3 \%-4 \%)$ is the most commonly used agent in topical monotherapy. New topical agents are being

\section{Melasma}

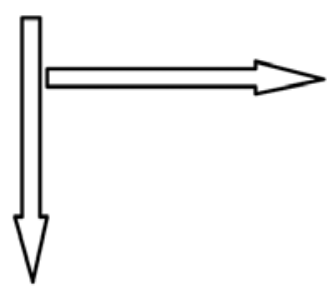

Sun protection +++

Interruption of hormonal

therapy +/-

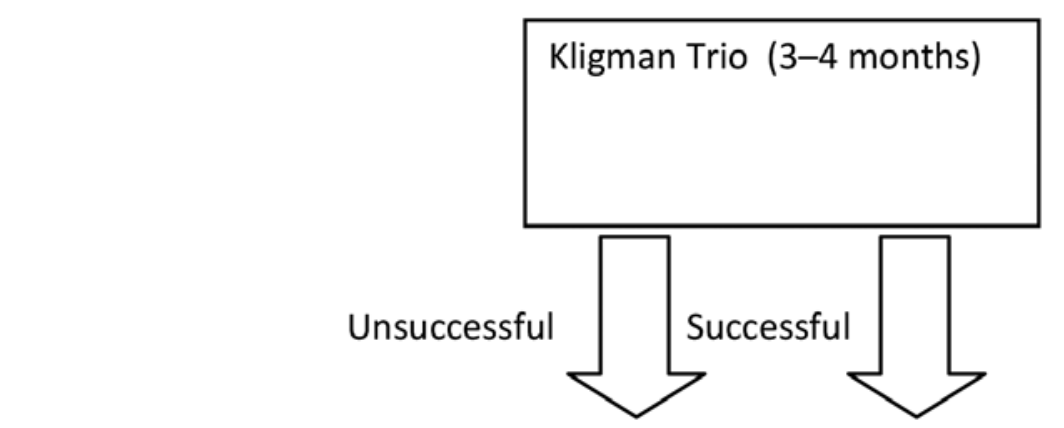

Peeling (PIH risk)

$1550 \mathrm{~nm}$ fractional laser (PIH risk) Ablative fractional laser+hydroquinone (or Kligman's formula), but repetitions

Pulse dye laser (PIH risk)

TA

Topical EDNRB inhibitors

Chemical approaches to prevent visible light induced pigmentation
Maintenance therapy Sun protection Cosmetic depigmentation cream

$$
\}
$$

Verification is

Will be determined 
developed in the treatment, but the effects are comparable to $\mathrm{HQ}$, and $\mathrm{HQ}$ is quite inexpensive. Although there are studies that report successful treatment with a Q-switched Nd: YAG laser with low fluence, this option should be considered for carefully selected resistant cases and should be combined with topical treatment. It can be considered for non-responsive or partially responsive cases to conventional treatment of oral TA, but studies are required to examine the efficacy and safety of this treatment. Development of new treatments is promising. Conventional, newly improved, and improving therapies in the treatment of melasma are summarized in Figure 1 (43). The fact that the number of randomized controlled trials regarding the treatment is low, the methodology of the trials is poor, the lack of standardized assessment measurements, and the short duration of these studies make the available data inadequate. However, the importance of dermal changes and vascularization in pathogenesis will lead to the development of new treatment options.

Peer-review: Externally peer-reviewed.

Conflict of Interest: No conflict of interest was declared by the author.

Financial Disclosure: The author declared that this study has received no financial support.

\section{References}

1. Dessinioti C, Lotti TM, Stratigos AJ , Damevska K,and Katsambas AD. Melasma.In: Katsambas AD, Lotti TM , Dessinioti C,D'erme AM,editors.Europen Handbook Dermatological Treatments. Springer-Verlag, Berlin Heidelberg 2015.p 613-9.

2. Rodrigues M, Pandya AP. Melasma: clinical diagnosis and management options. Austral J Dermatol 2015; 56: 151-63. [CrossRef]

3. Sivayathorn A. Melasma in Orientals. Clin Drug Invest 1995; 10(Suppl 2): 34-40.

4. Halder RN, Grimes PE, McLaurin CI, Kress MA, Kenney JA Jr. Incidence of common dermatoses in a predominantly black dermatologic practice. Cutis 1983; 32: 388-90.

5. Sheth VM, Pandya AG. Melasma: a comprehensive update: part I. J Am Acad Dermatol 2011; 65: 689-97. [CrossRef]

6. Eshghi G, Khezrian L, Esna Ashari F. Comparison between Intralesional Triamcinolone and Kligman's Formula in Treatment of Melasma. Acta Med Iran 2016; 54: 67-71.

7. Ortonne JP, Arellano I, Berneburg M, Cestari T, Chan H, Grimes P, et al. A global survey of the role of ultraviolet radiation and hormonal influences in the development of melasma J Eur Acad Dermatol Venereol 2009; 23: 1254-62.

8. Moin A, Jabery Z, Fallah N. Prevalence and awareness of melasma during pregnancy. Int J Dermatol 2006; 45: 285-8. [CrossRef]

9. Kim EH, Kim YC, Lee ES, Kang HY. The vascular characteristics of melasma. J Dermatol Sci 2007; 46: 111-6. [CrossRef]

10. Passeron T. Melasma pathogenesis and influencing factors - an overview of the latest research. J Eur Acad Dermatol Venereol 2013; 27(Suppl 1): 5-6.

11. Kang HY, Bahadoran P, Suzuki I, Zugaj D, Khemis A, Passeron $\mathrm{T}$, et al. In vivo reflectance confocal microscopy detects pig- mentary changes in melasma at a cellular level resolution. Exp Dermatol 2010; 19: e228-33.

12. Kim NH, Choi SH, Lee TR, Lee CH, Lee AY. Cadherin 11 Involved in Basement Membrane Damage and Dermal Changes in Melasma. Acta Derm Venereol 2016; 96: 635-40. [CrossRef]

13. Lee AY. Recent progress in melasma pathogenesis. Pigment Cell Melanoma Res 2015; 28: 648-60. [CrossRef]

14. Mahmoud BH, Ruvolo E, Hexsel CL, Liu Y, Owen MR, Kollias $\mathrm{N}$, et al. Impact of long-wavelength UVA and visible light on melanocompetent skin. J Invest Dermatol 2010; 130: 20927. [CrossRef]

15. Lowe NJ, Rizk D, Grimes P, Billips M, Pincus S. Azelaic acid 20\% cream in the treatment of facial hyperpigmentation in darkerskinned patients. Clin Ther 1998; 20: 945-59. [CrossRef]

16. Verallo-Rowell VM, Verallo V, Graupe K, Lopez-Villafuerte L, Garcia-Lopez M. Double-blind comparison of azelaic acid and hydroquinone in the treatment of melasma. Acta Derm Venereol Suppl (Stockh) 1989; 143: 58-61.

17. Balina LM, Graupe K. The treatment of melasma $20 \%$ azelaic acid versus 4\% hydroquinone cream. Int J Dermatol 1991; 30: 893-5. [CrossRef]

18. Farshi S. Comparative study of therapeutic effects of $20 \%$ azelaic acid and hydroquinone $4 \%$ cream in the treatment of melasma. J Cosmet Dermatol 2011; 10: 282-7. [CrossRef]

19. Griffiths CE, Finkel LJ, Ditre CM, Hamilton TA, Ellis CN, Voorhees JJ. Topical tretinoin (retinoic acid) improves melasma. A vehicle-controlled, clinical trial. Br J Dermatol 1993; 129: 415-21. [CrossRef]

20. Dogra S, Kanwar AJ, Parsad D. Adapalene in the treatment of melasma: a preliminary report. J Dermatol 2002; 29: 539-40. [CrossRef]

21. Draelos ZD. Skin lightening preparations and the hydroquinone controversy. Dermatol Ther 2007; 20: 308-13. [CrossRef]

22. Amer M, Metwalli M. Topical liquiritin improves melasma. Int J Dermatol 2000; 39: 299-301. [CrossRef]

23. Khemis A, Kaiafa A, Queille-Roussel C, Duteil L, Ortonne JP. Evaluation of efficacy and safety of rucinol serum in patients with melasma: a randomized controlled trial. Br J Dermatol 2007; 156: 997-1004. [CrossRef]

24. Malek J, Chedraoui A, Nikolic D, Barouti N, Ghosn S, Abbas $\mathrm{O}$. Successful treatment of hydroquinone-resistant melasma using topical methimazole. Dermatol Ther 2013; 26: 69-72. [CrossRef]

25. Adalatkhah H, Sadeghi-Bazargani $H$. The first clinical experience on efficacy of topical flutamide on melasma compared with topical hydroquinone: a randomized clinical trial. Drug Des Devel Ther 2015; 9: 4219-25.

26. Ferreira Cestari T, Hassun K, Sittart A, de Lourdes Viegas M. A comparison of triple combination cream and hydroquinone $4 \%$ cream for the treatment of moderate to severe facial melasma. J Cosmet Dermatol 2007; 6: 36-9. [CrossRef]

27. Guevara IL, Werlinger KD, Pandya AG. Tolerability and efficacy of a novel formulation in the treatment of melasma. J Drugs Dermatol 2010; 9: 215-8.

28. Guevara IL, Pandya AG. Safety and efficacy of $4 \%$ hydroquinone combined with $10 \%$ glycolic acid, antioxidants, and sunscreen in the treatment of melasma. Int J Dermatol 2003; 42: 966-72. [CrossRef]

29. Lee MH, Kim HJ, Ha DJ, Paik JH, Kim HY. Therapeutic effect of topical application of linoleic acid and lincomycin in 
combination with betamethasone valerate in melasma patients. J Korean Med Sci 2002; 17: 518-23. [CrossRef]

30. Grimes PE. The safety and efficacy of salicylic acid chemical peels in darker racial-ethnic groups. Dermatol Surg 1999; 25: 18-22. [CrossRef]

31. Sofen B, Prado G, Emer J. Melasma and Post Inflammatory Hyperpigmentation: Management Update and Expert Opinion. Skin Therapy Lett 2016; 21: 1-7.

32. Sheth VM, Pandya AG. Melasma: a comprehensive update: part II. J Am Acad Dermatol 2011; 65: 699-715. [CrossRef]

33. Bogdan Allemann I, Kaufman J. Fractional photothermolysis-an update. Lasers Med Sci 2010; 25: 137-44. [CrossRef]

34. Arora P, Sarkar R, Garg VK, Arya L. Lasers for treatment of melasma and post-inflammatory hyperpigmentation. J Cutan Aesthet Surg 2012; 5: 93-103. [CrossRef]

35. Rahman Z, Alam M, Dover JS. Fractional Laser treatment for pigmentation and texture improvement. Skin Therapy Lett 2006; 11: 7-11.

36. Passeron T, Fontas E, Kang HY, Bahadoran P, Lacour JP, Ortonne JP. Melasma treatment with pulsed-dye laser and triple combination cream: a prospective, randomized, single-blind, split-face study. Arch Dermatol 2011; 147: 1106-8. [CrossRef]

37. Cho HH, Choi M, Cho S, Lee JH. Role of oral tranexamic acid in melasma patients treated with IPL and low fluence QS Nd:YAG laser. J Dermatolog Treat 2013; 24: 292-6. [CrossRef]
38. Shin JU, Park J, Oh SH, Lee JH. Oral tranexamic acid enhances the efficacy of low-fluence 1064-nm quality-switched neodymium-doped yttrium aluminum garnet laser treatment for melasma in Koreans: a randomized, prospective trial. Dermatol Surg 2013; 39: 435-42. [CrossRef]

39. Leminen H, Hurskainen R. Tranexamic acid for the treatment of heavy menstrual bleeding: efficacy and safety. Int J Womens Health 2012; 4: 413-21.

40. Na JI, Choi SY, Yang SH, Choi HR, Kang HY, Park KC. Effect of tranexamic acid on melasma: a clinical trial with histological evaluation. J Eur Acad Dermatol Venereol 2013; 27: 1035-9. [CrossRef]

41. Padhi T, Pradhan S. Oral Tranexamic Acid with FluocinoloneBased Triple Combination Cream Versus Fluocinolone-Based Triple Combination Cream Alone in Melasma: An Open Labeled Randomized Comparative Trial. Indian J Dermatol 2015; 60: 520. [CrossRef]

42. Imokawa $G$ and Ishida K. Inhibitors of Intracellular Signaling Pathways that Lead to Stimulated Epidermal Pigmentation: Perspective of Anti-Pigmenting Agents. Int J Mo Sci 2014; 15: 8293-315. [CrossRef]

43. Passeron T. Melasma and its treatments.Pigmentary disorders (D1T03.2) . 25th Congress of European Academy of Dermatology and Venerology (October 8,2015,Copenhagen, Denmark (Speaking). 